\title{
Rights, mobility, and cohesion as building blocks for regional integration
}

Regional integration is generally discussed in terms of supranational political cooperation and the integration of economic markets. Since its inception, this journal has noted that political and academic discussions of regionalism focus more on the integration of territories and markets than on the role that people play in these processes. This issue of Regions $\mathcal{E} \mathrm{Co}^{-}$ hesion directly addresses this by "bringing the people back in."

When the Berlin Wall fell in 1990, Western Europe braced itself for an invasion of migrants that never came. History repeated itself when the European Union (EU) enlarged to the East in 2004 and once again fears of mass migrations never materialized. In fact, many observers of European politics have asked why the EU is characterized by so little internal mobility given the right to free circulation within the Union.

While many political officials may feel that a bullet was dodged because competition for jobs or demographic pressures on national welfare states never materialized, this trend in "European society" (if we may be so bold as to refer to a "European" society) actually points to the limits of European integration processes. The limited mobility in Europe actually illustrates the difficulties that exist with "European citizenship" (Threlfall, 2003). Now that the global financial crisis has created political schisms in Europe over the rights and responsibilities that member states face as a result of the economic woes in Greece, Spain, Ireland, Italy, etc., many scholars claim that warning signs already existed that indicated that "two Europes" were present on the continent rather than one (Magone, 2012). The lack of mobility on the continent was definitely one of these signs.

In fact, migration is generally discussed in political and academic discussions as a problem to be resolved. This position highlights how marginalized migration is in development and regional integration debates. Outdated push-pull theories are often utilized as the basis for considerations aimed at managing/controlling "North-South" flows. This vision, however, is misguided, in our opinion, because it alienates migrants from political and economic processes aimed at strengthening integration at the regional and global levels. 
Among the different (sub)regional regimes in the world, the EU and the African Union (AU) have established the most aggressive strategies of fostering intra-regional mobility and embedding this phenomenon in regional models of development (African Union, 2006). These organizations have achieved, however, only moderate success. In the case of the $\mathrm{AU}$, the legal framework for the promotion of mobility is weak as the African Common Position on Migration and Development (2006) only sets out guidelines and is not binding. Conversely, one should expect to find more mobility in the EU because the Schengen Accords are legal instruments that protect individuals' right to free circulation between signatory states. Why then, does one find similar intra-regional migration patterns within these regions?

This issue of Regions $\mathcal{E}$ Cohesion also focuses on an important aspect of region-building processes that is often overlooked: the question of rights. Rights are one of the pillars of citizenship and as such, they are often viewed to be exclusive goods that separate citizens and non-citizens which need to be protected by national governments. Of course, this view contradicts human rights that are often cited as part of the normative foundations of region-building. Moreover, national visions of rights negatively impact efforts to establish regional unions by controverting strategies aimed at fostering regional social cohesion.

All of the articles presented in this issue address these concepts. A recurring theme in these texts is the need for "bottom-up" integration to emerge in different world regions. Two of the articles, those by Robert Compton and Ndangwa Noyoo, examine regional-building processes in Southern Africa in comparative perspective. Compton analyzes how the Southern African Development Community (SADC) and the Association of Southeast Asian Nations (ASEAN) address social cohesion and human rights issues, especially when they need to be reconciled with broader regional integration objectives. He compares SADC's "regional compliance model" to ASEAN's "constructive engagement" approach. Noyoo's analysis focuses on SADC and argues that regional integration included social cohesion norms through the period of decolonization but it has ignored such traditions since then by focusing on neo-liberal models of economic integration. He contends that social cohesion is present in Southern Africa and it should be adopted more forcefully by the region's leaders to further integration goals.

Two other articles in this issue deal more directly with the notion of social rights, mobility and region-building. First, Bob Deacon and Sonja Nita compare regional social rights in Europe and Southern Africa. The article shows that in the EU the formal reality of free movement is substantially curtailed by problems with the portability of and access to social 
benefits. In SADC, migrants' access to social protection and social services show remarkable similarity to the EU. Access to social assistance is missing in both regions for some movers. The authors demonstrate how this similar characteristic affects mobility and social cohesion and ultimately undermines political objectives related to decision-making. Similarly, Alison Lee's contribution to this issue focuses on the notion of "illegality" and how Mexican migrants whom she has interviewed have been forced to return to Mexico because of the health problems that have in part been caused by their situations in the US. Because these migrants have limited access to health care in the US, they must return to Mexico where they can rely on the support of family or friends. The ethnographic research presented here clearly demonstrates the negative human impacts of migration which occur because of the lack of social rights in the US and Mexico.

Finally, it is important to mention that human rights must receive greater attention in comparative reflections on region-building and development. Like other regional organizations, the Andean Community of Nations lists respect for human rights as one of its guiding principles. Nonetheless, implementation within member states has been difficult. In her contribution to the Leadership Forum, Sara Fernández Moreno documents legal and political difficulties associated with Colombia's human rights response to victims of forced internal displacement, especially women who have suffered from sexual violence related to their forceddisplacement condition in armed conflict scenarios. This case documents problems associated with human rights protection amongst mobile populations, even within national contexts.

"Bottom-up regional integration" is often invoked when observers wish to mobilize greater citizen participation in region-building processes. However, real "bottom-up" processes are already occurring, in the form of human mobility within regions. This mobility often occurs in the informal sector because regional organizations have not developed strategies to incorporate this movement into regional development. In order to do so, however, regional regimes need to expand their notions of social rights and implement human rights. By doing so, they could reinforce regional social cohesion and thus, further the legitimacy and stability of regional governance.

The editors

\section{BIBLIOGRAPHY}

African Union. (2006). African common position on migration and development. Addis Ababa, Ethiopia: African Union. 
Magone, J. (2012). The European Union in a brave new world: The never ending tale of the Eurocrisis and the Southern Periphery. Lecture presented at the University of Luxembourg, May 21.

Threlfall, M. (2003). European social integration: Harmonization, convergence and single social areas. Journal of European Social Policy, 13 (2), 121-139. 